\title{
Effective Production of Hyaluronic Acid Oligosaccharides from Hyaluronic Acid
}

\author{
Ryoji MITSUI $^{\dagger}$, Toyoki OKADA, Tomoya SHIRAI and Mitsuo TANAKA \\ Department of Biochemistry, Faculty of Science, Okayama University of Science, \\ 1-1 Ridai-cho, Okayama, Okayama 700-0005, Japan
}

\begin{abstract}
The hyaluronidase-mediated degradation of hyaluronic acid to hyaluronic acid oligosaccharides was investigated. The final products of the batch reaction were the tetrasaccharide and hexasaccharide only. In the reaction solution containing an inorganic salt such as $\mathrm{NaCl}$, the yield of hexasaccharide was higher than that of tetrasaccharide. However, in the absence of inorganic salt, the tetrasaccharide was generated preferentially. The yield of each oligosaccharide depended on the nature of the inorganic salt used. In the batch reaction, the product yield was approximately $60 \%$. However, a continuous reaction increased the yield to about $85 \%$ within the first $200 \mathrm{~h}$ of operation.
\end{abstract}

Key words: hyaluronic acid, hyaluronidase, hyaluronic acid oligosaccharides, batch reaction, continuous reaction

\section{Introduction}

Hyaluronic acid is a linear, high molecular mass molecule, composed of the repeating disaccharide unit, $\beta-1,3-$ $N$-acetylglucosaminyl $\beta-1,4$-glucuronide. It is an important glycosaminoglycan component found mainly in connective tissues such as cartilage and joints.

There has been renewed interest in the synthesis of hyaluronic acid oligosaccharides since the recent publication of a report linking these molecules of 3 to 12 disaccharide units with the suppression of local tumors [3]. A number of microorganisms are known to possess enzymes which decompose hyaluronic acid. However, the number of the repeating disaccharide unit as final products can vary depending on the origin of the enzyme which was produced by microorganisms. Shimada and Matsumura [1] and Park et al. [2] investigated the process by which hyaluronic acid is degraded by hyaluronidase isolated from Streptomyces sp. They reported that octasaccharides obtained during the degradation process were the substrates of minimum size for the enzyme, and that tetra-and hexa-saccharides were not degraded further and accumulated as the final products. The molar ratio of tetrasaccharide to hexasaccharide was $c a .1$ to 1.2 .

In this study, we found that the ionic strength of the reaction solution significantly influenced the molar ratio of

(Received 29 Aug 2003: accepted 9 Dec 2003)

† Tel: 086-256-9708, Fax: 086-256-9559, E-mail: rmitsui@dbc.ous.ac.jp the final products. Furthermore, we examined the most effective conditions for producing oligosaccharides in both a continuous and a batch type reaction.

\section{Materials and Methods}

\section{1 Materials}

Hyaluronidase derived from Streptomyces sp. and sodium hyaluronic acid (average molecular weight of $>800,000$ ) were provided by Amano Enzyme Co. (Nagoya, Japan), and Maruha Co. (Tokyo, Japan), respectively. Protein was removed from the reaction mixture using a Centricut V-10 filter unit (Kurabou Co., Osaka, Japan).

\section{2 Batch reaction}

The reaction solution of $50 \mathrm{~mL}$ was prepared using sodium acetate buffer $(0.02 \mathrm{M}, \mathrm{pH}$ 6.0) containing $\mathrm{NaCl}(0.15$ $\mathrm{M})$. The hyaluronic acid substrate was dissolved in the buffer at a concentration of $1.0 \%(\mathrm{w} / \mathrm{v})$. Hyaluronidase was used at a final concentration of $16 \mathrm{TRU} / \mathrm{mL}$; where one TRU (turbidity reducing unit) is defined as the amount of enzyme which causes a 50\% reduction in absorbance at 660 $\mathrm{nm}$ in $30 \mathrm{~min}$ at $60^{\circ} \mathrm{C}$. All batch reactions were done at $40^{\circ} \mathrm{C}$. At regular time intervals, an aliquot of the reaction solution was sampled and the enzyme removed by centrifugation through a Centricut V-10 filter unit $(3,000 \mathrm{x} g$ for $40 \mathrm{~min}$ at $4^{\circ} \mathrm{C}$ ). The recovered filtrate was analyzed by high-performance liquid chromatography (HPLC) using a TSK-Gel DEAE-5PW column (Tosoh Co., Tokyo, Japan) 


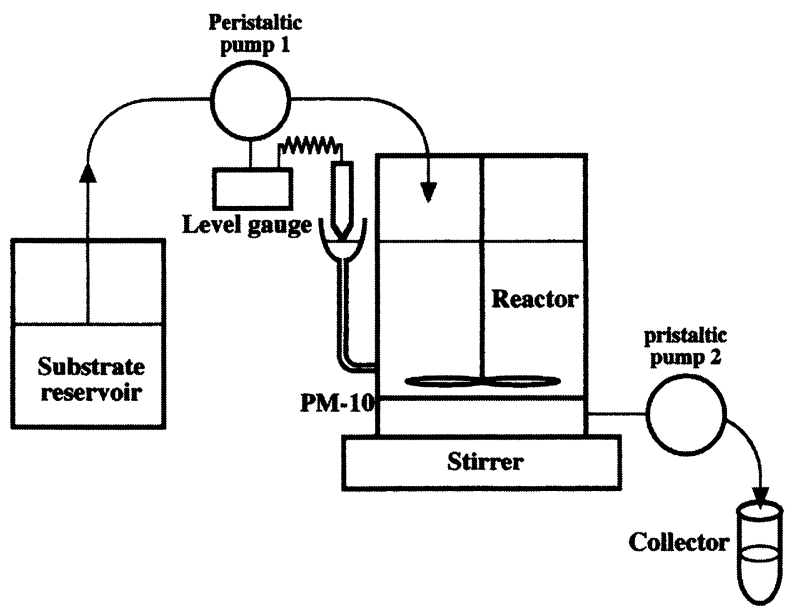

Fig. 1 Outline of the continuous reaction system.

fitted with a refractive index detector. HPLC was carried out under the following conditions: flow rate, $1.0 \mathrm{~mL} / \mathrm{min}$; column temperature, $40^{\circ} \mathrm{C}$; eluent composition, $50 \mathrm{mM}$ $\mathrm{NaCl}$. To study the effect of inorganic salts on the enzymatic degradation of hyaluronic acid, $\mathrm{KCl}, \mathrm{MgCl}_{2}, \mathrm{MgSO}_{4}$, $\mathrm{FeSO}_{4}$ or $\mathrm{FeCl}_{2}(0.15 \mathrm{M}$ each) was used instead of $\mathrm{NaCl}$.

\section{3 Continuous reaction}

Figure 1 shows an outline of the continuous reaction system [4]. The continuous reaction was performed in a reaction solution of $50 \mathrm{~mL}$ at either $40^{\circ} \mathrm{C}$ or $60^{\circ} \mathrm{C}$. The enzyme and residual substrate were kept in the reactor by the membrane (PM10, cut-off molecular mass: 10,000). The working volume in the reactor was kept constant by connecting the liquid surface controller (Level gauge SA107; Fujiwara Co., Tokyo, Japan) and the peristaltic pump 1. Hyaluronic acid solution $(1.0 \% \mathrm{w} / \mathrm{v})$ in sodium acetate buffer (0.02 M, pH 6.0) and $0.15 \mathrm{M} \mathrm{NaCl}$ was kept in the substrate reservoir and fed via peristaltic pump 1 to the reactor containing hyaluronidase (final concentration either 16 or $32 \mathrm{TRU} / \mathrm{mL}$ ). The flow rate at the inlet and outlet of the reactor was $1 \mathrm{~mL} / \mathrm{h}$. The reaction was initiated by pumping hyaluronic acid solution into the reactor. The reaction products were transferred to the collector via peristaltic pump 2 . The concentration of the products was measured by HPLC.

\section{Results and Discussion}

\section{1 Batch reaction}

Figure 2 shows the effect of the addition of $\mathrm{NaCl}$ to the production of oligosaccharides. When the reaction solution contained $0.15 \mathrm{M} \mathrm{NaCl}$, the concentration of tetrasaccharide was lower than that of hexasaccharide regardless of the reaction period, and the molar ratio of the former to the

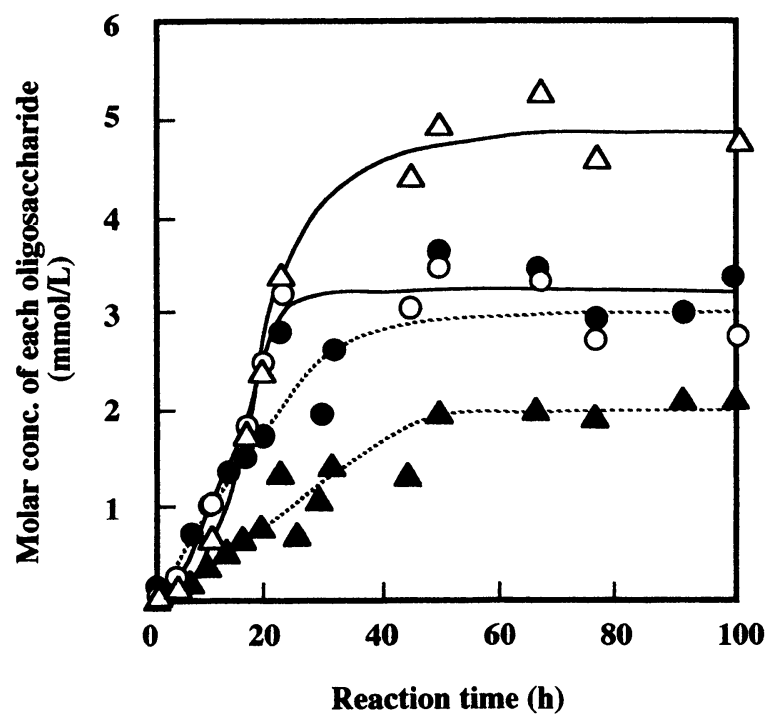

Fig. 2 Time course of the hyaluronidase-mediated degradation of hyaluronic acid in the absence or presence of $\mathrm{NaCl}$ $(0.15 \mathrm{M})$. The enzyme concentration was $16 \mathrm{TRU} / \mathrm{mL}$ and the reaction temperature $40^{\circ} \mathrm{C}$. Symbols: $\bigcirc$ and $\bigcirc$ represent the concentration of hexasaccharide in the presence or absence of $\mathrm{NaCl}$, respectively; $\boldsymbol{\Delta}$ and $\Delta$ represent the concentration of tetrasaccharide in the presence or absence of $\mathrm{NaCl}$, respectively.

latter was approximately $c a .1$ to $1.2 \sim 1.3$. The other saccharides were not detected during the reaction period. The molar yield of the oligosaccharides was very similar to the result described previously [2]. The yield of both oligosaccharides (tetrasaccharide: $2.2 \mathrm{mg} / \mathrm{mL}$ and hexasaccharide: $3.6 \mathrm{mg} / \mathrm{mL}$ ) was approximately $60 \%$. When the reaction was performed in the absence of $\mathrm{NaCl}$, the ratio of oligosaccharide product was reversed (i.e. more tetrasaccharide than hexasaccharide). This interesting result suggests that $\mathrm{NaCl}$ in the reaction solution influenced the mechanism of enzymatic degradation of hyaluronic acid. Therefore, the effect of the addition of several inorganic salts on the enzymatic degradation of hyaluronic acid was examined (Table 1). When we substituted $\mathrm{NaCl}$ in the reaction solution for other inorganic salts, the yield of hexasaccharide was higher than that of tetrasaccharide. The enzyme activity and the molar yield of tetra-and hexa-saccharide depended on whether inorganic salts were present or not.

Table 1 Concentration and yield of oligosaccharide produced.

\begin{tabular}{cccccccc}
\hline $\begin{array}{c}\text { Inorganic salts added } \\
(0.15 \mathrm{M})\end{array}$ & None & $\mathrm{NaCl}$ & $\mathrm{KCl}$ & $\mathrm{MgCl}_{2}$ & $\mathrm{MgSO}_{4}$ & $\mathrm{FeSO}_{4}$ & $\mathrm{FeCl}_{2}$ \\
\hline Tetrasaccharide (g/L) & 3.3 & 2.2 & 2.4 & 2.0 & 1.4 & 0 & 0 \\
Hexasaccharide (g/L) & 2.8 & 3.6 & 4.6 & 4.4 & 2.8 & 1.2 & 0 \\
\hline Yield (\%) & 61 & 58 & 70 & 64 & 42 & 12 & 0 \\
\hline
\end{tabular}




\section{2 Continuous reaction}

In the batch procedure, the reaction appeared to reach equilibrium after about $40 \mathrm{~h}$, and the yield of oligosaccharides was approximately $60 \%$. Therefore, if the oligosaccharide product could be efficiently removed from the reaction solution, further degradation of hyaluronic acid might be expected. We constructed a reactor in which the enzyme was retained by an ultrafiltration membrane, which allowed us to perform a continuous reaction. Figure 3 shows the time course of production of hyaluronic acid oligosaccharides. When the reaction was carried at $40^{\circ} \mathrm{C}$ using $32 \mathrm{TRU} / \mathrm{mL}$ of hyaluronidase, the concentration of the product at the outlet reached a steady state after about $100 \mathrm{~h}$. During a $200-\mathrm{h}$ reaction we obtained $c a .1400$ $\mathrm{mg}$ of oligosaccharide product $(560 \mathrm{mg}$ tetrasaccharide and $820 \mathrm{mg}$ hexasaccharide) corresponding to a $70 \%$ yield. The steady state can be maintained for approximately 400-h (data not shown), although prolonging the reaction further results in adsorption of residual substrate to the surface of the membrane. However, we detected no enzyme inactivation during the $400-\mathrm{h}$ operation period. When the reaction was carried at $60^{\circ} \mathrm{C}$, maintaining other

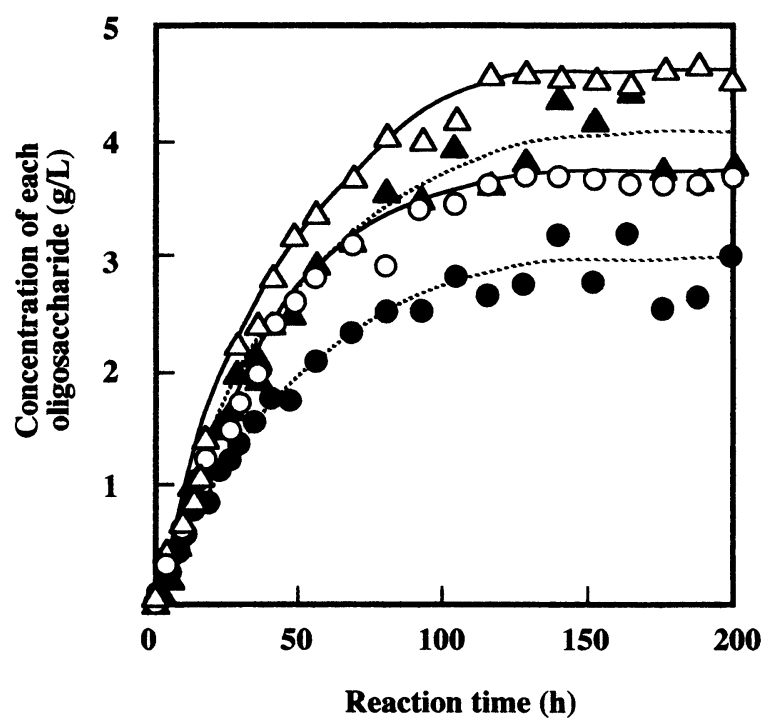

Fig. 3 Time course of product formation in the continuous reactor. Concentration of hyaluronidase was $32 \mathrm{TRU} / \mathrm{mL}$. The buffer in the reaction solution contained $\mathrm{NaCl}(0.15 \mathrm{M})$. The concentration of hyaluronic acid in the reservoir was $10 \mathrm{~g} / \mathrm{L}$. The concentration of each oligosaccharide represents the value at the outlet of the reactor. Symbols: $\bigcirc$ and $\bigcirc$ represent the concentration of hexasaccharide at $40^{\circ} \mathrm{C}$ or $60^{\circ} \mathrm{C}$ of the reaction temperature, respectively; $\boldsymbol{\Delta}$ and $\triangle$ represent the concentration of tetrasaccharide at $40^{\circ} \mathrm{C}$ or $60^{\circ} \mathrm{C}$ of the reaction temperature, respectively. operational conditions as described above, we obtained $c a$. $1700 \mathrm{mg}$ of oligosaccharide product (760 mg tetrasaccharide and $950 \mathrm{mg}$ hexasaccharide) corresponding to a $85 \%$ yield during a $200-\mathrm{h}$ reaction. These results indicate that the yield of product significantly increased at the elevated reaction temperature. However, raising the temperature to increase the yield is technically difficult in a continuous process because of the increased rate of evaporation of the reaction solution.

\section{Conclusions}

The detectable products from the degradation of hyaluronic acid with the Streptomyces hyaluronidase were only hexa-and tetrasaccharides. When the reaction was carried out in the presence of $\mathrm{NaCl}$, more hexasaccharide was produced than tetrasaccharide, but in the absence of $\mathrm{NaCl}$, the product ratio was reversed. A similar trend was also observed using different salts. The observations are of interest in terms of producing these biologically important oligosaccharides although the mechanism of the reaction remains to be solved.

To improve the yield of oligosaccharide a continuous reaction was performed. The oligosaccharides were obtained in high yield (approximately 85\%) after $200 \mathrm{~h}$ of reaction at $60^{\circ} \mathrm{C}$. There was no detectable inactivation of the enzyme during this operation period. Although the continuous process initially generated product efficiently, longer-term reaction ( $>400 \mathrm{~h}$ ) was made difficult by adsorption of residual substrate to the filter.

\section{References}

1) E. Shimada, G. Matsumura; Degradation of hyaluronic acid by Streptomyces hyaluronidase, J. Biochem., 88, 1015-1023 (1980).

2) Y. Park, S. Cho, R. J. Linhardt; Exploration of the action pattern of Streptomyces hyaluronate lyase using highresolution capillary electrophoresis, Biochim. Biophys. Acta, 1337, 217-226 (1997).

3) C.Zeng, B.P.Toole, S.D. Kinney, J.-w. Kuo, I. Stamenkovic; Inhibition of tumor growth in vivo by hyaluronan oligomers, Int. J. Cancer, 77, 396-401 (1998).

4) M. Tanaka; Continuous production of cellobiose by cellulose hydrolysis with cellulase and theoretical consideration on the hydrolysis process, The Bull. Okayama Univ. of Sci., 36 (A), 217-223 (2000). 